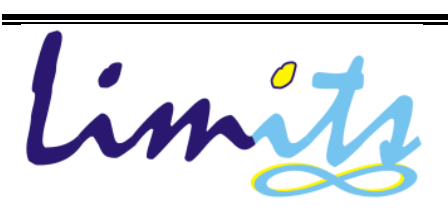

J. Math. and Its Appl.

E-ISSN: 2579-8936

P-ISSN: $1829-605 \mathrm{X}$

Vol. 15, No. 2, Nopember 2018, 141-150

\title{
Analisa Peningkatan Pelayanan Teller Dan Customer Service Bank Menggunakan Fuzzy Logic
}

\author{
Said Munzir ${ }^{1)}$, Nur Aulia Zannah' ${ }^{1)}$, dan Mahmudi ${ }^{1)}$ \\ ${ }^{1)}$ Jurusan Matematika FMIPA UNSYIAH
}

\begin{abstract}
Abstrak
Pada sistem antrian nasabah bank konvesional, jika pembagian pelayan customer service dan teller tidak sesuai dengan nasabah yang mengantri mengakibatkan nasabah mendapatkan waktu menunggu yang sangat lama pada antrian yang sedang ramai. Dalam penelitian ini digunakan sistem fuzzy logic Sugeno untuk menganalisa banyak pelayan customer service dan banyak pelayan teller yang dibutuhkan sesuai dengan nasabah yang mengantri agar antrian nasabah lebih efisiensi. Sistem ini dirancang berdasarkan data nasabah yang mengantri pada setiap petugas pelayanan bank di BRI Cabang Banda Aceh, dari tanggal 2 sampai 31 Mei 2017, untuk berbagai kondisi kepadatan antrian yang terjadi. Dari sistem fuzzy yang dibangun dapat dianalisa banyak pelayan yang dibutuhkan sesuai dengan nasabah yang mengantri. Jika antrian di customer service 10 orang dan antrian di teller 61 orang maka banyak pelayan customer service yang dibutuhkan adalah 3 orang dan banyak pelayan teller yang dibutuhkan adalah 5 orang. Dengan banyak pelayan tersebut waktu yang dibutuhkan untuk melayani nasabah menggunakan sistem fuzzy logic Sugeno lebih cepat dari pada menggunakan sistem bank konvesional sehingga dapat mengurangi waktu menunggu di customer service sebesar $2.5 \%$ dan teller sebesar $27.78 \%$. Hasil penelitian ini menunjukkan bahwa sistem fuzzy logic Sugeno mampu meningkatkan efisiensi antrian nasabah.
\end{abstract}

Kata kunci: pelayan customer service dan teller, antrian nasabah, sistem fuzzy logic Sugeno, sistem bank konvesional.

\begin{abstract}
In the conventional bank's customer queue system, if the partition for customer service and teller was not balanced it would cause a long waiting time in crowded customer's queue. In this research it is used Sugeno's fuzzy logic system for analyze a number of customer service and teller for efficiency of customer's queue. This system designed based on data about customer's queue for each customer services at BRI Banda Aceh branch, starting date from May $2^{\text {nd }}$ until $31^{\text {st }}$ 2017, for various queuing density conditions that occur. From the fuzzy system which is built, it can be analyzed that many servants are needed according to the customers who are queuing. If the queue at customer service is 10 people and the queue at the teller is 61 people, there are 3 customer service servants and 5 tellers, based on those number, the time needed to serve customers using Sugeno's fuzzy logic system is faster than using a conventional bank system so that it can reduce the wait time at customer service by $2.5 \%$ and tellers by $27.78 \%$. The results of this study indicate that Sugeno's fuzzy logic system is able to improve the efficiency of customer queues.
\end{abstract}


Keywords: services from customer service and teller, customer queue, Sugeno's fuzzy logic system, conventional bank system

\section{Pendahuluan}

Sejalan dengan semakin ketatnya tingkat persaingan antar bank, maka setiap bank harus berusaha meningkatkan kemampuan daya saingnya. Salah satu usaha untuk meningkatkan daya saing, pihak bank harus memperhatikan dan memberikan kualitas layanan yang prima kepada nasabahnya. Nasabah sering menilai kualitas sistem operasi suatu bank berdasarkan lamanya waktu menunggu dalam memberikan pelayanan kepada para nasabahnya. Pada umumnya setiap nasabah mengharapkan untuk segera mendapatkan pelayanan tanpa harus menunggu atau mengantri terlalu lama.

Pelayanan adalah suatu proses pemenuhan kebutuhan melalui aktifitas orang lain secara langsung [1]. Pada dasarnya setiap manusia membutuhkan pelayanan, bahkan secara ekstrim dapat dikatakan bahwa pelayanan tidak dapat dipisahkan dengan kehidupan manusia. Pelayanan merupakan bagian dari sebuah jasa. Pelayanan adalah suatu kegiatan atau proses menyampaikan jasa kepada pemakai jasa [2].

Pelayanan kepada nasabah bank dapat diberikan oleh customer service maupun teller. Sehingga antrian yang terjadi di bank biasanya terbagi menjadi dua, yaitu antrian menuju customer service dan antrian menuju teller. Antrian timbul disebabkan oleh nasabah yang mebutuhkan pelayanan melebihi kemampuan (kapasitas) pelayanan, sehingga nasabah yang tiba tidak bisa segera mendapat pelayanan disebabkan kesibukan pelayan tersebut.

Pembagian pelayan customer service dan pelayan teller yang tidak sesuai dengan nasabah yang mengantri mengakibatkan antrian yang sedang ramai nasabah mendapatkan waktu menunggu untuk mendapatkan pelayanan yang sangat lama, sedangkan antrian di tempat lain yang sedang sepi nasabah mendapatkan waktu menunggu untuk mendapatkan pelayanan yang lebih cepat, padahal setiap nasabah sama-sama membutuhkan pelayanan yang cepat.

Oleh karena itu, perlu adanya pengaturan petugas pelayanan nasabah bank (pelayan customer service dan teller). Hal ini bertujuan untuk memperoleh banyak pelayan yang sesuai dengan nasabah yang mengantri agar antrian nasabah lebih efisiensi. Dalam hal ini diasumsikan petugas pelayanan bank dapat bekerja dalam berbagai bidang keahlian yaitu dapat menjadi customer service maupun teller. Apabila nasabah yang mengantri di customer service sepi, sedangkan nasabah yang mengantri di teller ramai maka pelayan customer service dapat 
membantu pelayan teller dalam melayani nasabah. Sehingga nantinya nasabah tidak harus menunggu terlalu lama.

Dalam penelitian ini digunakan sistem fuzzy logic Sugeno untuk menganalisa pelayan customer service dan pelayan teller yang dibutuhkan sesuai dengan nasabah yang mengantri. Tujuan penelitian ini adalah menganalisa pelayan customer service dan teller yang dibutuhkan sesuai dengan nasabah yang mengantri. Selanjutnya menghitung waktu yang dibutuhkan pelayan tersebut untuk melayani semua nasabah dengan menggunakan sistem fuzzy dan membandingkan efisiensi dari hasil simulasi antrian nasabah sistem fuzzy logic Sugeno dengan sistem bank konvesional.

\section{Metode Penelitian}

Penelitian ini dilakukan pada kasus di Bank Rakyat Indonesia (BRI) Kantor Wilayah Banda Aceh, alamat Jl. Cut Meutia No.17 Banda Aceh. Data yang digunakan dalam penelitian ini adalah data nasabah yang mengantri pada setiap petugas pelayanan bank seperti customer service dan teller di Bank Rakyat Indonesia (BRI) Cabang Banda Aceh. Data tersebut merupakan data primer yang diperoleh dengan cara mengamati dan mencatat setiap nasabah yang datang dan membutuhkan pelayanan di Bank BRI tersebut. Setelah itu, dengan menggunakan data antrian nasabah dan fuzzy logic Sugeno, akan di analisa banyak pelayan customer service dan teller yang dibutuhkan sesuai dengan nasabah yang mengantri pada setiap pelayan tersebut.

Data yang diambil yaitu jumlah nasabah yang mengantri pada setiap petugas pelayanan bank, data tersebut digunakan untuk penentuan variabel input. Data rata-rata waktu pelayanan dari setiap petugas pelayanan bank yang digunakan sebagai pedoman dalam pembuatan fungsi keanggotan pada variabel input. Selain itu, data jumlah petugas pelayanan bank yang digunakan untuk penentuan variabel output. Data yang dikumpulkan adalah jumlah nasabah yang mengantri, waktu menunggu nasabah dalam antrian, waktu pelayanan yang diberikan customer service dan teller, banyak pelayan customer service dan pelayan teller.

Pengolahan data pada penelitian ini menggunakan fuzzy inference system (FIS) metode Sugeno dengan menggunakan fuzzy logic toolbox yang ada pada MATLAB R2010a. Untuk mendapatkan output dari FIS diperlukan tahapan-tahapan sebagai berikut :

- Penentuan variabel input dan output

- $\quad$ Pembentukan fungsi keanggotaan untuk setiap variabel input 
- $\quad$ Pembentukan konstanta atau persamaan linier variabel output. Variabel output banyak pelayan customer service dan banyak pelayan teller dibagi menjadi 3 yang berupa 1 konstanta dan 2 persamaan linear.

- $\quad$ Pembuatan aturan fuzzy

- Defuzzifikasi

\section{Hasil dan Pembahasan}

Data untuk menganalisa pelayanan nasabah bank BRI Kantor Wilayah Banda Aceh terdiri atas 2 variabel yaitu antrian nasabah dan banyak pelayan bank yang dibutuhkan. Data tersebut diperoleh dengan cara mengamati dan mencatat banyak petugas pelayanan bank dan rata-rata waktu pelayanan dari setiap petugas tersebut dalam rentang waktu 1 jam. Dalam data tersebut ada 2 petugas pelayanan bank yang akan diteliti yaitu customer service dan teller. Data hasil pengamatan dapat dilihat pada Tabel 1. dibawah ini.

Tabel 1. Banyak pelayan dan rata-rata waktu pelayanan

\begin{tabular}{|l|c|c|}
\hline Petugas pelayanan & $\begin{array}{c}\text { Banyak } \\
\text { pelayan }\end{array}$ & $\begin{array}{c}\text { Rata-rata waktu } \\
\text { pelayanan (menit) }\end{array}$ \\
\hline Customer Service & 4 & 20 \\
\hline Teller & 4 & 5 \\
\hline
\end{tabular}

Data diatas merupakan kondisi sistem antrian yang digunakan bank sekarang ini yaitu dengan menggunakan banyak pelayan yang sama untuk setiap nasabah yang mengantri dan menurut hasil penelitian itu tidak terlalu baik dikarenakan setiap petugas pelayanan bank tidak memiliki jumlah nasabah mengantri yang selalu sama. Berdasarkan data hasil pengamatan tersebut dapat ditentukan nasabah yang dapat dilayani setiap pelayan dan semua pelayan dalam rentang waktu 1 jam, seperti pada Tabel 2. dibawah ini.

Tabel 2. Nasabah yang dapat dilayani pelayan bank

\begin{tabular}{|l|c|c|}
\hline Petugas pelayanan & $\begin{array}{c}\text { Nasabah yang dapat } \\
\text { dilayani setiap pelayan }\end{array}$ & $\begin{array}{c}\text { Nasabah yang dapat } \\
\text { dilayani semua pelayan }\end{array}$ \\
\hline Customer Service & 3 & 12 \\
\hline Teller & 12 & 48 \\
\hline
\end{tabular}

Dari Tabel 1 dan 2 di atas terlihat bahwa 4 pelayan customer service dapat melayani 12 orang nasabah yang mengantri di customer service dan 4 pelayan teller dapat melayani 48 orang nasabah yang mengantri di teller dalam rentang waktu 1 jam. Jika nasabah yang mengantri pada salah satu petugas pelayanan lebih sedikit dari itu maka banyak pelayan juga harus dikurangi 
dari jumlah tersebut dan sisa pelayan yang lainnya dapat membantu petugas pelayanan yang lain yang memiliki antrian nasabah yang lebih banyak agar waktu menunggu nasabah dalam mengantri tidak terlalu lama.

Variabel input yang digunakan dalam penelitian ini adalah antrian di customer service dan antrian di teller, sedangkan untuk variabel output adalah banyak pelayan customer service dan banyak pelayan teller (Tabel 3). Penelitian ini menggunakan metode Sugeno, jadi variabel input yang digunakan berupa himpunan fuzzy sedangkan variabel output berupa konstanta atau persamaan linear (Tabel 4).

Tabel 3. Variabel input

\begin{tabular}{|c|c|c|c|c|}
\hline \multirow{7}{*}{ Input } & Variabel & $\begin{array}{c}\text { Nama } \\
\text { Himpunan fuzzy }\end{array}$ & $\begin{array}{c}\text { Semesta } \\
\text { Pembicaraan }\end{array}$ & Domain \\
\hline & \multirow{3}{*}{$\begin{array}{l}\text { Antrian di } \\
\text { Customer Service }\end{array}$} & Sedikit & \multirow{3}{*}[0;24]{} & {$[0 ; 12]$} \\
\hline & & Sedang & & {$[8 ; 16]$} \\
\hline & & Banyak & & {$[12 ; 24]$} \\
\hline & \multirow{3}{*}{ Antrian di Teller } & Sedikit & \multirow{3}{*}[0;96]{} & {$[0 ; 48]$} \\
\hline & & Sedang & & {$[32 ; 64]$} \\
\hline & & Banyak & & {$[48 ; 96]$} \\
\hline
\end{tabular}

Tabel 4. Variabel output

\begin{tabular}{|c|c|c|c|}
\hline \multirow{7}{*}{ Output } & Variabel & $\begin{array}{c}\text { Jumlah Pelayan Konstan } \\
\text { Atau Fungsi Linear Dari } \\
\text { Jumlah Antrian }\end{array}$ & $\begin{array}{c}\text { Semesta } \\
\text { Pembicaraan }\end{array}$ \\
\hline & \multirow{3}{*}{$\begin{array}{l}\text { Banyak Pelayan } \\
\text { Customer Service }\end{array}$} & 4 & \multirow{3}{*}[0;8]{} \\
\hline & & $0.333 * \mathrm{CS}$ & \\
\hline & & $8-0.083 *$ Teller & \\
\hline & \multirow{3}{*}{$\begin{array}{l}\text { Banyak Pelayan } \\
\text { Teller }\end{array}$} & 4 & \multirow{3}{*}[0;8]{} \\
\hline & & $0.083 *$ Teller & \\
\hline & & $8-0.333 * \mathrm{CS}$ & \\
\hline
\end{tabular}

Untuk proses memfuzzikan input maka langkah pertama adalah membentuk fungsi keanggotaan. Fungsi keanggotaan menyatakan derajat keanggotaan suatu variabel yang dinyatakan dengan suatu bilangan rill dalam selang tertutup [0,1]. Dengan perkataan lain, fungsi keanggotaan dari suatu himpunan kabur $\tilde{A}$ dalam semesta $X$ adalah pemetaan $\mu_{\tilde{A}}: X \rightarrow[0,1]$ dari $X$ ke selang $[0,1]$ yaitu $\mu_{\tilde{A}}: X \rightarrow[0,1]$. Nilai fungsi $\mu_{\tilde{A}}(x)$ menyatakan derajat keanggotaan unsur $x \in X$ dalam himpunan kabur $\tilde{A}[3]$. 
Adapun beberapa fungsi keanggotaan fuzzy dapat dinyatakan sebagai [4]: linier, segitiga, trapesium dan bahu. Pembentukan fungsi keanggotaan untuk variabel input pada penelitian ini menggunakan fungsi keanggotaan bentuk bahu dan segitiga, yang secara rinci dilakukan sebagai berikut:

1. Antrian di customer service

Pada variabel antrian di customer service, himpunan fuzzy dibagi menjadi 3 yaitu SEDIKIT, SEDANG, dan BANYAK yang dapat dilihat pada Gambar 1. berikut :

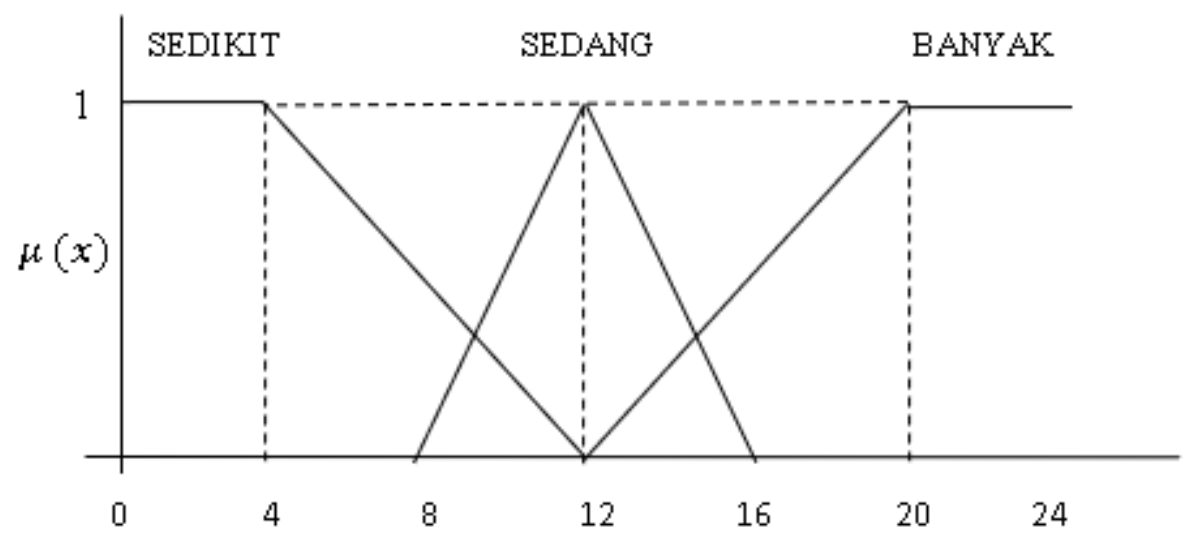

Gambar 1. Representasi antrian di customer service

2. Antrian di teller

Pada variabel antrian di teller, himpunan fuzzy dibagi menjadi 3 yaitu SEDIKIT, SEDANG, dan BANYAK yang dapat dilihat pada Gambar 2 berikut :

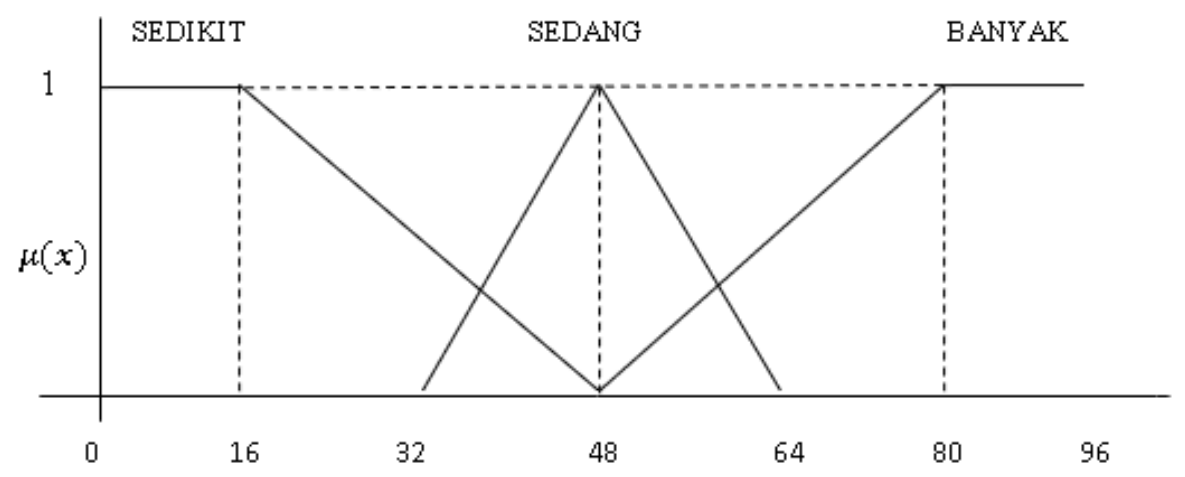

Gambar 2. Representasi antrian di teller 
Variabel output dalam penelitian ini yaitu banyak pelayan yang dibutuhkan pada setiap pelayanan bank, sehingga memiliki 2 variabel output yaitu : banyak pelayan customer service dan banyak pelayan teller.

Tabel 5 dibawah ini adalah hasil analisa pelayanan nasabah bank dengan menggunakan sistem fuzzy logic Sugeno dan MATLAB R2010a. Hasil tersebut berupa banyak pelayan yang dibutuhkan sesuai dengan jumlah nasabah yang mengantri dalam waktu 1 jam, sehingga dapat dihitung waktu yang dibutuhkan pelayan tersebut untuk melayani semua nasabah dengan menggunakan sistem fuzzy.

Tabel 5. Hasil analisa pelayanan nasabah bank menggunakan sistem fuzzy logic Sugeno pada customer service

\begin{tabular}{|c|c|c|c|c|c|c|}
\hline \multirow{2}{*}{ Tanggal } & \multirow{2}{*}{$\begin{array}{l}\text { Antrian } \\
\text { (orang) }\end{array}$} & \multirow{2}{*}{$\begin{array}{l}\text { Banyak } \\
\text { Pelayan } \\
\text { (konven } \\
\text { sional) }\end{array}$} & \multirow{2}{*}{$\begin{array}{c}\text { Banyak } \\
\text { Pelayan } \\
(f u z z y)\end{array}$} & \multicolumn{2}{|c|}{$\begin{array}{c}\text { Waktu yang } \\
\text { dibutuhkan untuk } \\
\text { melayani semua } \\
\text { nasabah (menit) }\end{array}$} & \multirow{2}{*}{$\begin{array}{l}\text { Perbandinga } \\
\mathrm{n} \text { antara } \\
\text { sistem fuzzy } \\
\text { dan bank } \\
\text { saat ini }(\%)\end{array}$} \\
\hline & & & & $\begin{array}{c}\text { Sistem } \\
\text { bank } \\
\text { konvension } \\
\text { al }\end{array}$ & $\begin{array}{l}\text { Sistem } \\
\text { fuzzy }\end{array}$ & \\
\hline 2 Mei & 10 & 4 & 3 & 82 & 80 & 2.5 \\
\hline $3 \mathrm{Mei}$ & 11 & 4 & 4 & 70 & 60 & 14.29 \\
\hline $4 \mathrm{Mei}$ & 15 & 4 & 5 & 113 & 60 & 46.9 \\
\hline $5 \mathrm{Mei}$ & 8 & 4 & 3 & 60 & 60 & 0 \\
\hline $15 \mathrm{Mei}$ & 9 & 4 & 3 & 58 & 60 & -3.45 \\
\hline $16 \mathrm{Mei}$ & 10 & 4 & 4 & 62 & 60 & 3.23 \\
\hline $17 \mathrm{Mei}$ & 12 & 4 & 5 & 80 & 60 & 25 \\
\hline $18 \mathrm{Mei}$ & 18 & 4 & 5 & 130 & 80 & 38.46 \\
\hline $29 \mathrm{Mei}$ & 13 & 4 & 6 & 90 & 60 & 33.33 \\
\hline $30 \mathrm{Mei}$ & 10 & 4 & 5 & 82 & 40 & 51.22 \\
\hline $31 \mathrm{Mei}$ & 9 & 4 & 4 & 76 & 60 & 21.05 \\
\hline 2 Juni & 18 & 4 & 4 & 103 & 100 & 2.91 \\
\hline 3 Agustus & 10 & 4 & 4 & 90 & 60 & 33.33 \\
\hline 4 Agustus & 7 & 4 & 3 & 59 & 60 & -1.11 \\
\hline
\end{tabular}

Pada Tabel 5. dapat dilihat tanggal 2 Mei 2017, nasabah yang mengantri di customer service 10 orang, waktu yang dibutuhkan untuk melayani semua nasabah jika menggunakan sistem bank konvesional adalah 82 menit. Sedangkan jika menggunakan sistem fuzzy logic Sugeno adalah 80 menit. Waktu yang dibutuhkan untuk melayani semua nasabah menggunakan sistem fuzzy logic Sugeno lebih cepat dari pada menggunakan sistem bank konvesional sehingga waktu menunggu nasabah untuk mendapatkan pelayanan akan berkurang. Hasil simulasi menggunakan sistem fuzzy logic Sugeno tersebut dapat mengurangi waktu menunggu sebesar 
2.5\%. Dari hasil penelitian, tidak semua yang menggunakan sistem fuzzy logic Sugeno dapat mengurangi waktu menunggu nasabah, ada 2 dari 14 peristiwa yang akan menambah waktu menunggu nasabah. Hal tersebut disebabkan karena pelayan yang seharusnya melayani antrian di customer service berpindah melayani antrian di teller.

Tabel 6. Hasil analisa pelayanan nasabah bank menggunakan sistem fuzzy logic Sugeno pada teller

\begin{tabular}{|c|c|c|c|c|c|c|}
\hline \multirow[b]{2}{*}{ Tanggal } & \multirow{2}{*}{$\begin{array}{l}\text { Antrian } \\
\text { (orang) }\end{array}$} & \multirow{2}{*}{$\begin{array}{l}\text { Banyak } \\
\text { Pelayan } \\
\text { (konven } \\
\text { sional) }\end{array}$} & \multirow{2}{*}{$\begin{array}{l}\text { Banyak } \\
\text { Pelayan } \\
(f u z z y)\end{array}$} & \multicolumn{2}{|c|}{$\begin{array}{l}\text { Waktu yang dibutuhkan } \\
\text { untuk melayani semua } \\
\text { nasabah (menit) }\end{array}$} & \multirow{2}{*}{$\begin{array}{l}\text { Perbandingan } \\
\text { antara sistem } \\
\text { fuzzy dan bank } \\
\text { saat ini }(\%)\end{array}$} \\
\hline & & & & $\begin{array}{c}\text { Sistem } \\
\text { bank } \\
\text { konvension } \\
\text { al }\end{array}$ & $\begin{array}{l}\text { Sistem } \\
\text { fuzzy }\end{array}$ & \\
\hline $2 \mathrm{Mei}$ & 61 & 4 & 5 & 90 & 65 & 27.78 \\
\hline $3 \mathrm{Mei}$ & 41 & 4 & 4 & 55 & 55 & 0 \\
\hline $4 \mathrm{Mei}$ & 35 & 4 & 3 & 58 & 60 & -3.45 \\
\hline $5 \mathrm{Mei}$ & 45 & 4 & 5 & 60 & 45 & 25 \\
\hline $15 \mathrm{Mei}$ & 45 & 4 & 5 & 60 & 45 & 25 \\
\hline $16 \mathrm{Mei}$ & 36 & 4 & 4 & 64 & 45 & 29.69 \\
\hline 17 Mei & 36 & 4 & 3 & 70 & 60 & 14.29 \\
\hline $18 \mathrm{Mei}$ & 32 & 4 & 3 & 64 & 55 & 14.06 \\
\hline $29 \mathrm{Mei}$ & 24 & 4 & 2 & 55 & 60 & -9.09 \\
\hline $30 \mathrm{Mei}$ & 30 & 4 & 3 & 58 & 50 & 13.79 \\
\hline $31 \mathrm{Mei}$ & 32 & 4 & 4 & 66 & 40 & 39.39 \\
\hline 2 Juni & 64 & 4 & 4 & 90 & 80 & 11.11 \\
\hline 3 Agustus & 45 & 4 & 4 & 80 & 60 & 25 \\
\hline 4 Agustus & 36 & 4 & 5 & 52 & 40 & 23.08 \\
\hline
\end{tabular}

Pada Tabel 6. dapat dilihat tanggal 2 Mei 2017, nasabah yang mengantri di teller 61 orang, waktu yang dibutuhkan untuk melayani semua nasabah jika menggunakan sistem bank konvesional adalah 90 menit. Sedangkan jika menggunakan sistem fuzzy logic Sugeno adalah 65 menit. Waktu yang dibutuhkan untuk melayani semua nasabah menggunakan sistem fuzzy logic Sugeno lebih cepat dari pada menggunakan sistem bank konvesional sehingga waktu menunggu nasabah untuk mendapatkan pelayanan akan berkurang. Hasil simulasi menggunakan sistem fuzzy logic Sugeno tersebut dapat mengurangi waktu menunggu nasabah sebesar $27.78 \%$. Dari hasil penelitian, tidak semua yang menggunakan sistem fuzzy logic Sugeno dapat mengurangi waktu menunggu nasabah, ada 2 dari 14 peristiwa yang akan menambah waktu menunggu nasabah. Hal tersebut disebabkan karena pelayan yang seharusnya melayani antrian di teller berpindah melayani antrian di customer service. 
Tabel 7 menjelaskan bahwa efisiensi rata-rata sistem fuzzy dibandingkan bank konvensional pada custumore service dan teller memiliki persentase lebih dari 5\%. Hal tersebut menyatakan bahwa waktu yang dibutuhkan untuk melayani semua nasabah menggunakan sistem fuzzy logic Sugeno lebih cepat, sehingga dapat mengurangi waktu menunggu nasabah dari pada menambah waktu menunggu. Hal ini membuat antrian nasabah hasil simulasi menggunakan sistem fuzzy logic Sugeno lebih efisien dibandingkan dengan antrian nasabah berdasarkan aturan yang ada saat ini di bank. Antrian nasabah dikatakan efisien apabila dapat melayani semua nasabah yang mengantri dengan menggunakan waktu yang lebih sedikit atau waktu menunggu yang digunakan nasabah dalam mengantri lebih cepat.

Tabel 7. Efisiensi rata-rata sistem fuzzy dibandingkan bank konvensional

\begin{tabular}{|c|c|c|c|c|c|c|c|}
\hline \multirow{2}{*}{ No } & \multicolumn{2}{|c|}{$\begin{array}{c}\text { Antrian } \\
\text { (orang) }\end{array}$} & \multicolumn{2}{c|}{$\begin{array}{c}\text { Banyak Pelayan } \\
\text { (fuzzy) }\end{array}$} & \multicolumn{2}{c|}{$\begin{array}{c}\text { Efisiensi sistem fuzzy } \\
\text { dibandingkan bank } \\
\text { konvensional (\%) }\end{array}$} & \begin{tabular}{c} 
Efisiensi \\
rata-rata \\
sistem \\
\cline { 2 - 7 }
\end{tabular} \\
\cline { 2 - 7 } & $\begin{array}{c}\text { Customer } \\
\text { Service }\end{array}$ & Teller & $\begin{array}{c}\text { Customer } \\
\text { Service }\end{array}$ & Teller & $\begin{array}{c}\text { Customer } \\
\text { Service }\end{array}$ & Teller & fuzzy) \\
\hline 1. & 10 & 61 & 3 & 5 & 2.5 & 27.78 & 14.75 \\
\hline 2. & 11 & 41 & 4 & 4 & 14.29 & 0 & 7.15 \\
\hline 3. & 15 & 35 & 5 & 3 & 46.9 & -3.45 & 21.73 \\
\hline 4. & 8 & 45 & 3 & 5 & 0 & 25 & 12.5 \\
\hline 5. & 9 & 45 & 3 & 5 & -3.45 & 25 & 10.78 \\
\hline 6. & 10 & 36 & 4 & 4 & 3.23 & 29.69 & 16.46 \\
\hline 7. & 12 & 36 & 5 & 3 & 25 & 14.29 & 19.65 \\
\hline 8. & 18 & 32 & 5 & 3 & 38.46 & 14.06 & 26.26 \\
\hline 9. & 13 & 24 & 6 & 2 & 33.33 & -9.09 & 24.24 \\
\hline 10. & 10 & 30 & 5 & 3 & 51.22 & 13.79 & 32.51 \\
\hline 11. & 9 & 32 & 4 & 4 & 21.05 & 39.39 & 30.22 \\
\hline 12. & 18 & 64 & 4 & 4 & 2.91 & 11.11 & 7.01 \\
\hline 13. & 10 & 45 & 4 & 4 & 33.33 & 25 & 29.17 \\
\hline 14. & 7 & 36 & 3 & 5 & -1.11 & 23.08 & 10.99 \\
\hline
\end{tabular}

\section{Simpulan}

Berdasarkan hasil penelitian dan pembahasan dapat diambil kesimpulan :

1. Sistem fuzzy logic Sugeno yang dibangun dapat mengestimasi banyaknya pelayan yang dibutuhkan sesuai dengan nasabah yang mengantri.

2. Waktu yang dibutuhkan untuk melayani nasabah menggunakan sistem fuzzy logic Sugeno sebagian lebih cepat dari pada menggunakan sistem bank konvesional sehingga jika jumlah antrian di customer service 10 orang dan jumlah antrian di teller 
61 orang dapat mengurangi waktu menunggu di customer service sebesar $2.5 \%$ dan teller sebesar $27.78 \%$.

3. Hasil penelitian menunjukkan bahwa sistem fuzzy logic Sugeno mampu meningkatkan efisiensi antrian nasabah.

\section{Daftar Pustaka}

[1] A. S. Monier, Managemen Pelayanan Umum di Indonesia. Jakarta: Bumi Aksara, 2006.

[2] L. P. Sinambela, Reformasi Pelayanan Publik, Teori, Kebijakan dan Implementasi. Jakarta: Bumi Aksara, 2006.

[3] Susilo and S. J. Fans, Himpunan dan Logika Kabur serta Aplikasinya. Yogyakarta: Graha Ilmu, 2006.

[4] R. Kruse, J. Gebhardt, and F. Klawonn, Foundation of Fuzzy Systems. Chichester: John Wiley and Sons, 1994. 